\title{
EFFICACY OF CLINICAL METHODS IN DETECTION OF INTRAUTERINE GROWTH RESTRICTION AMONG LOW RISK PREGNANT WOMEN
}

\author{
Bhavani G. ${ }^{1}$, Sabita P.2, Subashini M. ${ }^{3}$ \\ ${ }_{1}^{1}$ Postgraduate Student, Department of Obstetrics and Gynaecology, RGGW\&CH, Puducherry, India. \\ ${ }^{2}$ Associate Professor, Department of Obstetrics and Gynaecology, IGMC\&RI, Puducherry, India. \\ ${ }^{3}$ Specialist Grade-2, Department of Obstetrics and Gynaecology, RGGW\&CH, Puducherry, India.
}

\begin{abstract}
\section{BACKGROUND}

Nearly three fourth of all neonatal deaths and half of infant deaths occur among LBW infants. A progressive increase in both perinatal mortality and morbidity is observed as birth weight percentile falls. Early detection of intrauterine growth restriction is therefore important to institute specific treatment wherever possible or appropriately time the delivery. In a developing country like India, a simple sensitive clinical method is of utmost importance and cost effective. Hence this study is conducted to find the efficacy of clinical methods in detection of IUGR and estimation of foetal weight in relation to ultrasound.
\end{abstract}

\section{METHODS}

A longitudinal study of 200 low risk pregnant women who are attending the antenatal clinic with dating USG after 24 weeks of pregnancy were included in the study and serial symphysis fundal height measurements at each antenatal visit are taken. Suspected cases of growth restriction were subjected to USG for assessment and managed as per institutional protocol. Birth weight was compared with clinical and sonologically estimated weight. The entire data is statistically analysed using Statistical Package for Social Sciences (SPSS Ver. 21.0, IBM Corporation, USA) for MS Windows.

\section{RESULTS}

The sensitivity, specificity, PPV, NPV and accuracy of clinical method (abdominal palpation), clinical method (SFH), and USG method (abdominal circumference) USG method (Estimated Foetal Weight) in detecting IUGR was 80-95\% and their agreement with birth weight was statistically significant. The distribution of mean estimated weight by Johnson's formula is significantly higher compared to actual mean birth weight $(p$-value $<0.001)$. The distribution of mean estimated weight by USG is significantly higher compared to actual mean birthweight ( $p$-value<0.001). Since the mean difference in the weight is relatively lesser with narrow 95\% confidence interval by USG than Johnson's formula, USG method has relatively better method than Johnson's formula for estimation of weight.

\section{CONCLUSIONS}

The efficacy of serial symphysio-fundal height measurement was found to be comparable with ultrasound in detection of IUGR. Of the two methods studied for estimation of foetal weight, ultrasonographic method, i.e., Hadlock's formula has better predictable results in foetal weight estimation, compared to clinical method, i.e., Johnson's formula.

\section{KEY WORDS}

IUGR, Clinical Methods, Low Risk Pregnancies

HOW TO CITE THIS ARTICLE: Bhavani G, Sabita P, Subashini M. Efficacy of clinical methods in detection of intrauterine growth restriction among low risk pregnant women. J. Evolution Med. Dent. Sci. 2019;8(25):2018-2015, DOI: 10.14260/jemds/2019/443

\section{BACKGROUND}

Intrauterine growth restriction (IUGR) refers to a condition in which a foetus is unable to achieve its genetically determined potential size. Small for gestational age (SGA) is defined as growth at the 10th or less percentile for weight of all foetuses at that gestational age. Some of the SGA foetuses are constitutionally small and outcome is good however others have pathologically restricted growth. Similarly, babies who are appropriate for gestational age may not be reached its genetically determined growth potential.

'Financial or Other Competing Interest': None.

Submission 22-04-2019, Peer Review 07-06-2019,

Acceptance 14-06-2019, Published 24-06-2019.

Corresponding Author:

Dr. Sabita $P$.,

Type V-B, Q. No. 10

JIPMER Campus,

Puducherry-605006, India.

E-mail: sabita.kutty@gmail.com

DOI: $10.14260 /$ jemds $/ 2019 / 443$

\section{(c) $($ ) $\$$}

Hence the detection of IUGR according to its functional definition is very difficult and needs to identify a population of foetuses at risk for modifiable but otherwise poor outcomes. Rossavik and Deter, ${ }^{1}$ first proposed a mathematical model for foetal growth. So far, the literature has not provided convincing evidence that the Rossavik model is superior to computationally simpler models.

Since foetal growth retardation is difficult to assess, Small for gestational age (SGA) is often used as a proxy for IUGR. Consequently, fetuses with a birth weight of less than the 10th percentile of those born at the same gestational age or two standard deviation below the population mean, are considered growth restricted. However, fetuses which are less than 3rd to 5th percentile are clinically more relevant since they are more likely to have adverse effects. ${ }^{2}$

In India, of the 26 million born every year, 8 million are LBW infants i.e. around $40 \%$ of the global burden of LBW infants. Nearly three fourth of all neonatal deaths and half of infant deaths occur among LBW infants. A LBW baby is at higher risk of both mortality and morbidity compared to the normal birth weight infants. ${ }^{3}$ The perinatal mortality rate 
gives an index of obstetric and paediatric services available in a country. A progressive increase in both perinatal mortality and morbidity is observed as birth weight percentile falls. ${ }^{4}$

The early detection of intrauterine growth restriction is therefore important to institute specific treatment wherever possible or appropriate timed delivery to reduce neonatal morbidity and mortality.

Ultrasonography (USG) plays an important role in identifying growth restricted fetuses and in assessing intrauterine foetal wellbeing. In a developing country like India, sophisticated methods of monitoring are not available in all centers. So, a simple sensitive clinical method like gravid gram is of utmost importance. ${ }^{5}$

The serial symphysio-fundal height measurements are reported by Westin 6 to have $75 \%$ accuracy in detecting small for date infants, and symphysio-fundal height measurements were found to be superior to both HPL and urinary estriol in detecting retarded foetal growth. Though Clinical palpation using anatomical landmarks is subjective and has a wide interobserver difference (Bais 2004) In 1987, Pearce and Campbell ${ }^{7}$ reported that the sensitivity of the symphysiofundal height measurement (76\%) was only slightly less than that of a single measurement of foetal abdominal circumference by ultrasound in the third trimester (83\%) in the detection of intrauterine growth restriction. An impressive fall in perinatal mortality was demonstrated by Westin in 1977 following the introduction of the gravidogram.

SGA fetuses have higher incidence of foetal death, birth asphyxia, meconium aspiration, neonatal hypoglycaemia. To prevent or treat the foetal, neonatal and maternal morbidities and mortalities associated with SGA, accurate estimation of foetal weight is very important.

There are two common methods to estimate foetal weight; clinical methods (Includes palpation method, SFH measurement) and sonographic evaluation. Ultrasound study forms a very important tool in modern obstetrics. The accuracy of clinical methods of foetal weight estimation was similar to sonographic estimation at term. ${ }^{8,9,10}$ Clinical methods of estimation of foetal weight has been shown to be as good as ultrasound at term, giving estimates that are correct to within $10 \%$ of the birth weight in $60 \%$ to $70 \%$ of cases.

In developing countries, ultrasonography may be unavailable or may not be affordable by patients and clinical palpation of the abdomen in estimating foetal weight requires considerable experience and training. SFH measurement with a tape - measure seems a simple clinical method because it is cheap, readily available, non-invasive and acceptable to patients. ${ }^{11}$ Furthermore it is a reproducible technique that is easily learned.

After taking the SFH yet it still presents problems with conversion of a measurement to foetal weight estimate. A prediction formula for birth weight has been first deduced from SFH by Johnsonet al and they claimed an accuracy within $240 \mathrm{~g}$ in $68 \%$ and $375 \mathrm{gms}$ in $75 \%$ among 200 women examined.12,13 It was validated in different countries and most studies done have confirmed that Johnson's formula correctly predicts actual birth weight from 61 to $72 \% .^{14,15,16}$

A comparative study done in India in 2010 showed that Johnson's formula correctly predicts birth weight in $71 \%$ overall. $^{9}$
While according to a similar study done in India shows that Johnson's formula correctly predicts birth weight in $63.5 \%$ overall. 17

Hence this study is conducted to find the efficacy of clinical methods in detection of IUGR and estimation of foetal weight in relation to ultrasound.

\section{Aim}

To study the efficacy of clinical methods in detection of Intra uterine growth restriction among low risk pregnant women.

\section{Objectives}

1. To assess the efficacy of clinical methods in detection of IUGR in comparison to USG among low risk pregnant women

2. To assess the efficacy of Johnson's formula and ultrasound in estimation of foetal weight.

\section{METHODS}

The present study was carried out as a longitudinal study in, a tertiary care hospital, Puducherry. Total of 200 low risk pregnant women who are attending the antenatal clinic with dating USG after 24 weeks of pregnancy were included in the study after obtaining written \&informed consent.

Detailed history including age, parity, booking status, obstetrical, gynaecological, past, personal \& family history is taken. Period of gestation calculated by menstrual age were confirmed with dating USG. In addition to routine obstetric examination serial symphysis fundal height measurements at each antenatal visit are taken from 24 weeks onwards.

The women are examined supine after emptying their bladders. Symphysis fundal heights are measured with a nonstretch centimetre tape which gives foetal growth in weeks of pregnancy. Measurements are taken from the uterine fundus to the symphysis pubis according to the method described by Westin at different weeks of gestation from 24 weeks until delivery. At least five readings are taken per patient and plotted on a graph. These measurements were plotted on maternal symphysis-fundus growth chart

Fetuses were suspected to be growth restricted when the graph showed either a flattening or falling trend or the measurement was below $10^{\text {th }}$ percentile in the graph.

Those fetuses found to be small for gestational age as determined by serial SFH measurements were subjected to serial ultrasound examination for detection of growth restriction babies. Subjects who are diagnosed to have IUGR will be managed as per institution protocol. Other normal growth patients will be subjected to USG at 32 weeks to confirm the normal growth. Final USG will be done prior to delivery for Abdominal circumference and EFW. Birth weight of all the babies will be noted down for the comparison with estimated birth weight by JOHNSON 's formula and USG. Estimated foetal weight were compared with the weight of the baby at birth to compare the efficacy of both methods.

Foetal weight at birth for various gestational ages at delivery was taken according to the graph plotted for the south Indian population from Kerala as shown in the figure below. 

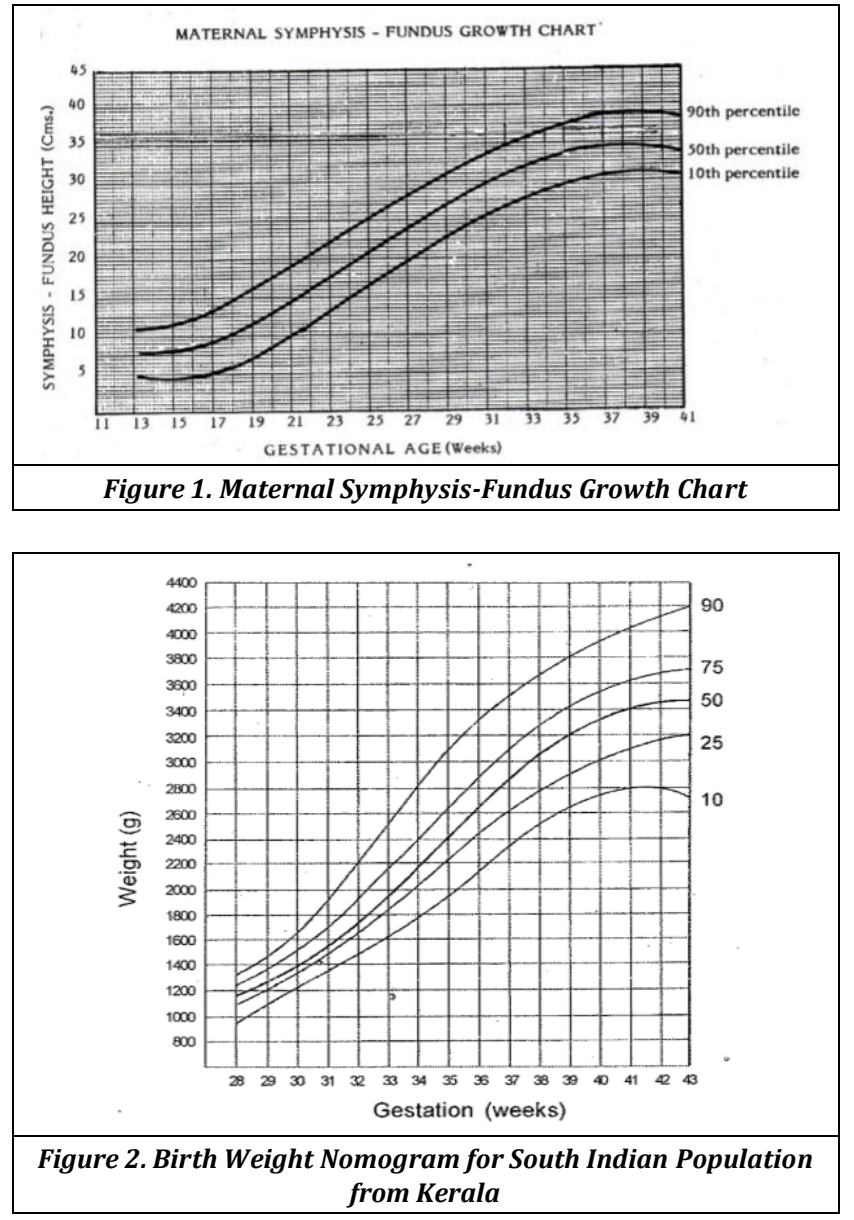

\section{RESULTS}

\begin{tabular}{|c|c|c|c|c|c|c|c|}
\hline \multirow{2}{*}{\multicolumn{2}{|c|}{$\begin{array}{l}\text { Sociodemographic } \\
\text { Factors }\end{array}$}} & \multirow{2}{*}{$\begin{array}{l}\text { Total } \\
\text { No. } \\
(200)\end{array}$} & \multicolumn{2}{|c|}{$\begin{array}{l}\text { SGA } \\
(51)\end{array}$} & \multicolumn{2}{|c|}{$\begin{array}{c}\text { AGA/LGA } \\
\text { (149) }\end{array}$} & \multirow[t]{2}{*}{ p-Value } \\
\hline & & & No. & $\%$ & No. & $\%$ & \\
\hline \multirow{4}{*}{$\begin{array}{c}\text { Age } \\
\text { (years) }\end{array}$} & $<19$ & 31 & 11 & 35.5 & 20 & 64.5 & \multirow[t]{4}{*}{$0.413^{\mathrm{NS}}$} \\
\hline & $20-25$ & 78 & 17 & 21.8 & 61 & 78.2 & \\
\hline & $26-30$ & 64 & 15 & 23.4 & 49 & 76.6 & \\
\hline & $>30$ & 22 & 7 & 31.8 & 15 & 68.2 & \\
\hline \multirow{4}{*}{ SES Class } & II & 10 & 2 & 20.0 & 8 & 80.0 & \multirow[t]{4}{*}{$0.342^{\mathrm{NS}}$} \\
\hline & III & 53 & 9 & 17.0 & 44 & 83.0 & \\
\hline & IV & 121 & 36 & 29.8 & 85 & 70.2 & \\
\hline & $\mathrm{V}$ & 16 & 4 & 25.0 & 12 & 75.0 & \\
\hline \multirow{5}{*}{ Gravida } & 1 & 77 & 23 & 29.9 & 54 & 70.1 & \multirow[t]{5}{*}{$0.258^{\mathrm{NS}}$} \\
\hline & 2 & 59 & 14 & 23.7 & 4 & 76.3 & \\
\hline & 3 & 38 & 6 & 15.8 & 32 & 84.2 & \\
\hline & 4 & 15 & 3 & 20.0 & 12 & 80.0 & \\
\hline & 5 & 11 & 5 & 45.5 & & 54.5 & \\
\hline \multirow{4}{*}{$\begin{array}{l}\text { Mother } \\
\text { Height } \\
\text { (Cms) }\end{array}$} & $140-144$ & 23 & 17 & 73.9 & 6 & 26.1 & \multirow[t]{4}{*}{$0.001^{* * *}$} \\
\hline & $145-149$ & 32 & 13 & 40.6 & 19 & 59.4 & \\
\hline & $150-154$ & 84 & 17 & 20.2 & 67 & 79.8 & \\
\hline & $>155$ & 61 & 4 & 6.6 & 57 & 93.4 & \\
\hline \multirow{4}{*}{$\begin{array}{l}\text { Mother } \\
\text { Pre } \\
\text { Pregnancy } \\
\text { Weight } \\
\text { In Kg }\end{array}$} & $<40$ & 15 & 9 & 60.0 & 6 & 40.0 & \multirow[t]{4}{*}{$0.005^{* *}$} \\
\hline & & 69 & 20 & 29.0 & 49 & 71.0 & \\
\hline & $45-49$ & 47 & 10 & 21.3 & 37 & 78.7 & \\
\hline & & & & 17.4 & 57 & & \\
\hline \multirow{4}{*}{ BMI } & $<18.5$ & 69 & 13 & 18.8 & 56 & 81.2 & \multirow[t]{4}{*}{$0.395^{\mathrm{NS}}$} \\
\hline & $18.5-22.9$ & 88 & 26 & 29.5 & 62 & 70.5 & \\
\hline & $23.0-24$ & 25 & 6 & 24.0 & 19 & 76.0 & \\
\hline & $25.0-29.9$ & 18 & 6 & 33.3 & 12 & 66.7 & \\
\hline \multirow{3}{*}{$\begin{array}{l}\text { Kg weight } \\
\text { Gain in } \\
\text { Pregnancy }\end{array}$} & $<6$ & 19 & 10 & 52.6 & 9 & 47.4 & \multirow[t]{3}{*}{$0.002^{* *}$} \\
\hline & & 121 & 33 & 27.3 & 88 & 72.7 & \\
\hline & $10-14$ & 60 & 8 & 13.3 & 52 & 86.7 & \\
\hline \multicolumn{8}{|c|}{$\begin{array}{l}\text { p-value by Chi-Square test. p-value }<0.05 \text { is considered to be statistically } \\
\text { significant. NS-Not Significant, } * * \text {-value }<0.01 \text { (Statistically Significant). } \\
{ }^{* * *} \text { p-value }<0.001 \text { (Highly Significant). }\end{array}$} \\
\hline \multicolumn{8}{|c|}{$\begin{array}{l}\text { Table 1. Distribution of IUGR According to Sociodemographic } \\
\text { Factors }\end{array}$} \\
\hline
\end{tabular}

\begin{tabular}{|c|c|c|c|c|c|c|c|}
\hline & \multirow{2}{*}{$\begin{array}{c}\text { Total } \\
\text { No. } \\
(200)\end{array}$} & \multicolumn{2}{|c|}{$\begin{array}{l}\text { SGA } \\
(51)\end{array}$} & \multicolumn{2}{|c|}{$\begin{array}{c}\text { AGA/LGA } \\
\text { (149) }\end{array}$} & \multirow[t]{2}{*}{ p-Value } \\
\hline & & & No. & $\%$ & No. & $\%$ & \\
\hline \multirow{3}{*}{$\begin{array}{c}\text { Gestational } \\
\text { Age } \\
\text { in Weeks }\end{array}$} & $35-36$ & 18 & 6 & $\begin{array}{l}33.3 \\
\end{array}$ & 12 & 66.7 & \multirow{3}{*}{$0.001^{* * *}$} \\
\hline & $37-38$ & 82 & 33 & 40.2 & 49 & 59.8 & \\
\hline & $\geq 39$ & 100 & 12 & 12.0 & 88 & 88.0 & \\
\hline \multirow{2}{*}{$\begin{array}{l}\text { Mode of } \\
\text { Delivery }\end{array}$} & Vaginal & 110 & 32 & 29.1 & 78 & 70.9 & \multirow{2}{*}{$0.254^{\mathrm{NS}}$} \\
\hline & LSCS & 90 & 19 & 21.1 & 71 & 78.9 & \\
\hline \multicolumn{8}{|c|}{$\begin{array}{l}\text { p-Value by Chi-Square test. p-value }<0.05 \text { is considered to be statistically } \\
\text { significant. }{ }^{* * *} \text {-value }<0.0011 \text { (Highly Significant).NS - Not significant }\end{array}$} \\
\hline
\end{tabular}

\begin{tabular}{|c|c|c|c|c|c|c|c|}
\hline \multirow[b]{2}{*}{ 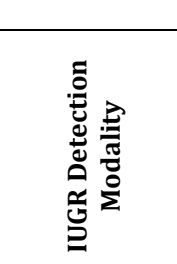 } & \multicolumn{7}{|c|}{ Diagnostic Efficacy Indices (\%) } \\
\hline & 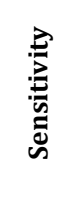 & 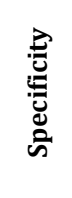 & 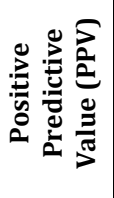 & 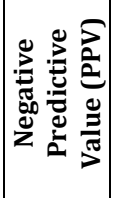 & 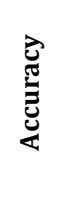 & 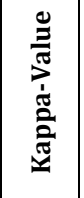 & 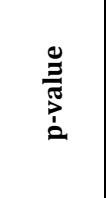 \\
\hline $\begin{array}{r}\text { Clinical ( } \\
\text { Palpatic }\end{array}$ & 86.3 & 87.9 & 70.9 & 94.9 & 87.5 & 0.693 & $0.001^{* * *}$ \\
\hline Clinical (SFH) & 84.3 & 97.3 & 91.5 & 94.8 & 94.0 & 0.838 & $0.001^{* * *}$ \\
\hline $\begin{array}{c}\text { USG (Abd } \\
\text { Circumference) }\end{array}$ & 88.2 & 93.3 & 81.8 & 95.9 & 92.0 & 0.795 & $0.001^{* * *}$ \\
\hline $\begin{array}{l}\text { USG (Estimated } \\
\text { Foetal Weight) }\end{array}$ & 92.2 & 81.2 & 62.7 & 96.8 & 84.0 & 0.635 & $0.001^{* * *}$ \\
\hline \multicolumn{8}{|c|}{$\begin{array}{l}\text { p-Value by Chi-Square test. p-value }<0.05 \text { is considered to be statistically } \\
\text { significant. *** p-value }<0.001 \text { (Highly Significant) }{ }^{*} \text {-value }<0.05 \\
\text { (Statistically Significant). Cohen-Kappa Statistics for testing agreement } \\
\text { between two techniques. }\end{array}$} \\
\hline $\begin{array}{r}\text { Table } \\
\text { ovestig } \\
\text { Alc }\end{array}$ & & & & & & & \\
\hline
\end{tabular}

\begin{tabular}{|c|c|c|c|c|c|c|c|}
\hline \multirow[b]{2}{*}{ 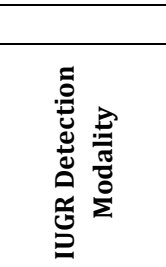 } & \multicolumn{7}{|c|}{ Diagnostic Efficacy Indices (\%) } \\
\hline & 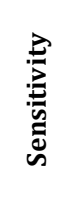 & 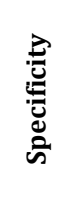 & 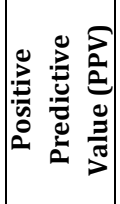 & 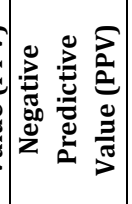 & $\frac{\overrightarrow{\mathscr{T}}}{\grave{E}}$ & 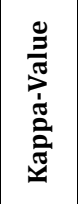 & 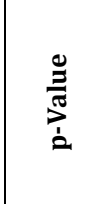 \\
\hline $\begin{array}{l}\text { Clinica } \\
\text { Palpa }\end{array}$ & 61.3 & 87.2 & 74.2 & 78.9 & 77.5 & 0.503 & $0.001^{* * *}$ \\
\hline Clinical (SFH) & 57.3 & 96.8 & 91.5 & 79.1 & 82.0 & 0.585 & $0.001^{* * *}$ \\
\hline \multicolumn{8}{|c|}{$\begin{array}{c}\text { p-value by Chi-Square test. p-value }<0.05 \text { is considered to be statistically } \\
\text { significant. }{ }^{* * *} \text {-value }<0.001 \text { (Highly Significant) }{ }^{*} \text {-value }<0.05 \\
\text { (Statistically Significant). Cohen-Kappa Statistics for testing agreement } \\
\text { between two techniques. }\end{array}$} \\
\hline $\begin{array}{r}\text { Table } \\
\text { Investigatic } \\
\text { Detection }\end{array}$ & iag & ता & cacy & aces of & 60 & 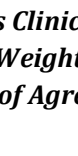 & ment \\
\hline
\end{tabular}

\begin{tabular}{|c|c|c|c|c|c|c|}
\hline \multicolumn{3}{|c|}{$\begin{array}{l}\text { Estimated Foetal Weight } \\
\text { (gm) BY } \\
\text { Mean } \pm \text { SD }(n=200)\end{array}$} & \multicolumn{2}{|c|}{$\begin{array}{c}\text { Difference (gm) } \\
\text { [Johnson's-Birth } \\
\text { Weight] }\end{array}$} & \multicolumn{2}{|c|}{$\begin{array}{l}\text { Difference (gm) } \\
\text { [USG-Birth } \\
\text { Weight] }\end{array}$} \\
\hline $\begin{array}{l}\text { Johnson's } \\
\text { Formula }\end{array}$ & USG & $\begin{array}{c}\text { Birth } \\
\text { weight } \\
\text { (Actual) }\end{array}$ & $\begin{array}{c}\text { Mean } \\
(95 \% \mathrm{CI})\end{array}$ & $\begin{array}{c}\text { p- } \\
\text { value }\end{array}$ & $\begin{array}{c}\text { Mean } \\
(95 \% \mathrm{CI})\end{array}$ & p-Valu \\
\hline $\begin{array}{c}2897.4 \pm \\
501.0\end{array}$ & $\begin{array}{l}2811.7 \\
\pm 488.8\end{array}$ & $\begin{array}{c}2767.4 \pm \\
501.0\end{array}$ & $\begin{array}{c}130.2 \\
{[102.0 \text { to }} \\
158.4]\end{array}$ & $0.001^{* * *}$ & $\begin{array}{c}44.3 \\
{[18.6 \text { to }} \\
69.9]\end{array}$ & $0.001^{* * *}$ \\
\hline \multicolumn{7}{|c|}{$\begin{array}{l}\mathrm{p} \text {-value by Paired } \mathrm{t} \text { test. p-value }<0.05 \text { is considered to be statistically } \\
\text { significant. }{ }^{* * *} \text {-value }<0.001 \text { [Highly Significant] }\end{array}$} \\
\hline $\begin{array}{l}\text { Table } \\
\text { Form }\end{array}$ & $m$ & 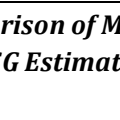 & $\begin{array}{r}\text { ed Foeta } \\
\text { Weight }\end{array}$ & & & \\
\hline
\end{tabular}




\section{Statistical Analysis}

The data on categorical variables is shown as $\mathrm{n}$ ( $\%$ of cases). The statistical significance of inter-group difference of distribution of categorical variables is tested using ChiSquare test or Fisher's exact probability test. The diagnostic efficacy indices such as sensitivity, specificity, positive predictive value (PPV), negative predictive value (NPV) and accuracy is determined for detection of IUGR by clinical and USG methods against birthweight as a gold standard. The statistical agreement between the methods is tested using Cohen Kappa Statistic.

The entire data is statistically analysed using Statistical Package for Social Sciences (SPSS Ver. 21.0, IBM Corporation, USA) for MS Windows.

Institute ethical committee clearance certification was sought and obtained before the study was begun.

\section{Relevant Tables}

The sensitivity, specificity, PPV, NPV and accuracy of clinical method (Abdominal palpation) in detecting IUGR was $86.3 \%$, $87.9 \%, 70.9 \%, 94.9 \%$ and $87.5 \%$ respectively the agreement between clinical method (Abdominal palpation) and Birth weight was statistically significant (Kappa value $=0.693$, $p$ value $<0.001$ ).

The sensitivity, specificity, PPV, NPV and accuracy of clinical method (SFH) in detecting IUGR was 84.3\%, 97.3\%, $91.5 \%, 94.8 \%$ and $94.0 \%$ respectively the agreement between clinical method (SFH) and Birth weight was relatively higher and statistically significant (Kappa value $=0.838$, $\mathrm{p}$-value $<0.001$ ).

The sensitivity, specificity, PPV, NPV and accuracy of USG method (abdominal circumference) in detecting IUGR was $88.2 \%, 93.3 \%, 81.8 \%, 95.9 \%$ and $92.0 \%$ respectively the agreement between USG method (Abdominal circumference) and Birth weight was statistically significant (Kappa value $=0.795$, p-value $<0.001$ ).

The sensitivity, specificity, PPV, NPV and accuracy of USG method (Estimated Foetal Weight) in detecting IUGR was $92.2 \%, 81.2 \%, 62.7 \%, 96.8 \%$ and $84.0 \%$ respectively the agreement between USG and Birth weight was statistically significant (Kappa value $=0.635$, $\mathrm{p}$-value $<0.001$ ).

The sensitivity, specificity, PPV, NPV and accuracy of clinical method (abdominal palpation) in detecting IUGR was $61.3 \%, 87.2 \%, 74.2 \%, 78.9 \%$ and $77.5 \%$ respectively the agreement between clinical method (Abdominal palpation) and USG (EFW) was statistically significant (Kappa value $=0.503$, p-value $<0.001$ ).

The sensitivity, specificity, PPV, NPV and accuracy of clinical method (SFH) in detecting IUGR was 57.3\%, 96.8\%, 91.5\%, 791\% and $82.0 \%$ respectively the agreement between clinical method (SFH) and USG (EFW) was statistically significant (Kappa value $=0.585$, $\mathrm{p}$-value $<0.001$ ) .

The distribution of mean estimated weight by Johnson's formula is significantly higher compared to actual mean birthweight ( $p$-value $<0.001$ ). The mean difference between the two methods is 130.2 gms with $95 \%$ CI of mean difference being 102.0 to 158.4 gms.

The distribution of mean estimated weight by USG is significantly higher compared to actual mean birthweight ( $p$ value $<0.001$ ). The mean difference between the two methods is 44.3 gms with $95 \%$ CI of mean difference being 18.6 to 69.9 gms.
Since the mean difference in the weight is relatively lesser with narrow 95\% confidence interval by USG than Johnson's formula, USG method has relatively better method than Johnson's formula for estimation of weight.

\section{DISCUSSION}

IUGR is one of the most important obstetrical complication which is contributing to the perinatal and neonatal morbidity and mortality. It is often under diagnosed complication especially in low risk pregnancies. The key step in prevention of foetal growth restriction (FGR) in low risk pregnancies is suspicion and early recognition. The regular assessment of growth can be done by various clinical and sonological methods. Sonological methods are found to be superior to clinical methods which are linked with expertise and cost. Cost effective health care interventions are need of the hour to reach the developmental goals in India. The key to management is likely to be optimizing the conditions of delivery and neonatal care by timely referrals. Hence this study was planned to find the efficacy of clinical methods in detection of fetuses with intrauterine growth restriction.

In this study 200 Antenatal women attending antenatal OPD in a tertiary care center were included for final analysis. We observed that age, socioeconomic status and gravidity of the mother did not have any statistically significant correlation with IUGR occurrence.

Though adolescent and elderly age group showed as a risk factors for IUGR in several studies ${ }^{18-23}$ in our study we observed only slight rise in incidence but NS statistically. Mumbare et $\mathrm{al}^{24}$ and Acharya $\mathrm{D}$ et $\mathrm{al}^{25}$ had similar results.

According to a study conducted by Muhammad et $\mathrm{al}^{19}$ in Pakistan Low SES of mothers was found to be significantly associated with IUGR.(OR=2.5, $\mathrm{CI}=1.4-4.4)$ Whereas a study conducted in Brazil26 showed a contradictory result.

In a study conducted by Ashwani $\mathrm{N}$ et ${ }^{21}$ al high prevalence of SGA babies is seen in multigravida. Majority of the studies $^{27-29}$ shows primigravida as a risk factor for IUGR however a study conducted in $\mathrm{Nepal}^{30}$ showed no such difference.

Maternal height, prepregnancy weight, and weight gain during pregnancy are found to be risk factors in our study whereas BMI did not show such correlation. In present study highest incidence of IUGR is associated with low maternal height and the association is consistent even with different studies. 19-21,24,27,31

In present study the highest incidence of IUGR was seen in maternal pre pregnancy weight $<40 \mathrm{Kgs}$. $(60 \%)$ and least among if maternal pre pregnancy weight $>49$ Kgs. (17.4\%)

The association is consistent with different studies. ${ }^{19,24,27.31}$

In the present study the distribution of prevalence of IUGR (as assessed by birthweight) did not differ significantly across various maternal BMI groups in the study group ( $p$ value $>0.05$ ).

In the present study the maximum incidence of FGR was found in women with weight gain less than $6 \mathrm{~kg}(52.6 \%) \mathrm{A}$ similar conclusion was seen in several studies. ${ }^{32-34}$

There was a significant association of preterm delivery and foetal growth restriction according to this study ( $p$-value $<0.001$ ).

In a retrospective analysis done by Goqiia $\mathrm{TE}, 35$ was documented that preterm birth is one of the risk factors of 
IUGR.A German study ${ }^{36}$ also quoted association of preterm delivery with IUGR. Zeitlin $\mathrm{J}^{37}$ stated that the relationship between growth restriction and preterm delivery is strongest for preterm births before 34 weeks of gestation. However, in this study most of the preterm births were induced for reasons other than premature rupture of membranes and the difference was observed in this group of premature infants. Hence the complication of pregnancy which resulted in iatrogenic preterm births may be the cause of intra uterine growth restriction rather than prematurity. However, the most common indication for caesarean section in women with growth restricted babies was foetal distress. In a study by Driul $\mathrm{L}$ et $\mathrm{al}^{38}$, it was found that women with intrauterine growth restriction underwent caesarean sections more often than women with appropriate foetal growth selected as controls $(\mathrm{P}<0.05)$.

\section{Clinical Methods}

Fundal height measurement by abdominal palpation is used historically to assess the growth of the fetus. With advent of Ultrasound, it lost its importance. However, in developing countries its role cannot be overlooked as USG is not feasible everywhere. Hence it is still considered as important tool for screening of FGR and recommended by some guidelines ${ }^{39}$ in suspecting FGR

In the present study the sensitivity of abdominal palpation was $86.3 \%$ and specify was $87.9 \%$. Positive predictive value was $70.9 \%$ and negative predictive value was $94.9 \%$ and the association was found to be stastically significant.

Rosenberg 40 in his study 73 (32\%) were suspected prenatally by abdominal palpation in a population of low and high-risk pregnancies whereas Kean and Liu selected a low risk for SGA as a study population and 61 women were suspected and 25 of these were SGA, sensitivity was $19 \%$, specificity $98 \%$. Hall et al ${ }^{41}$ described a detection rate of $44 \%$, sensitivity of $43.9 \%$, specificity of $87.8 \%$ due to antenatal detection" on inspection and palpation" in a combined low and high-risk group of 1884 women.

The sensitivity of serial symphysio-fundal height measurements was found to be $84.3 \%$ and the specificity was found to be $97.3 \%$. The positive predictive value was found to be $91.5 \%$ and negative predictive value found to be $94.8 \%$.

McDermott et al., in their review in the general population, found detection rate of FGR between $17 \%$ and $93 \%$ and a sensitivity of $65 \%$, for a $50 \%$ false positive rate. The wide variations are due to the methodology used and the presence of factors like high maternal BMI, uterine tumours (Leyomioma) or multiparity. 42.43

In 1999, Gardosi and Francis showed that detection rate of growth abnormalities can be doubled by plotting SFH on customized charts. ${ }^{44}$ Morse et al. presented a standardized protocol of SFH measurement by using non-elastic tape and plotting the values on customized charts doubled the detection rate of SGA.Despite the increased rate he showed a reduction in referrals for further investigation, by plotting on customized growth charts. hence there is reduction in false positives by using customised charts This finding corresponds to the reduction of false-positive diagnoses of IUGR based on EFW growth curves plotted on customised charts. ${ }^{39,44}$ but the 2012 Cochrane analysis by Peter et al. showed no benefit of using SFH for the detection of FGR, none the less fundal height measurements plotted on customised growth charts are still recommended by the RCOG Green Top Guidelines. ${ }^{45,46}$

In various studies the sensitivity of detection of foetal growth restriction by serial symphysio-fundal height measurement ranged from $26.6 \%$ (Perrson) to $92.5 \%$ by a study conducted at Madurai, India. The highest specificity for serial symphysio-fundal height measurement was found to be $99 \%$ by Muylder. The positive predictive value in various studies had a wider range of values, ranging from $14 \%$ (Challis ${ }^{47}$ ) to $90.6 \%$ (Walraven ${ }^{48}$ ). In the present study the negative predictive value was similar to the reports in literature.

\section{Ultrasound}

In the present study the sensitivity, specificity, PPV, NPV and accuracy of USG method (Abdominal circumference) in detecting IUGR was $88.2 \%, 93.3 \%, 81.8 \%, 95.9 \%$ and $92.0 \%$ respectively the agreement between USG method (Abdominal circumference) and Birth weight was statistically significant (Kappa value $=0.795$, $\mathrm{p}$-value $<0.001$ ).

The sensitivity, specificity, PPV, NPV and accuracy of USG method (Estimated Foetal Weight) in detecting IUGR was $92.2 \%, 81.2 \%, 62.7 \%, 96.8 \%$ and $84.0 \%$ respectively the agreement between USG and Birthweight was statistically significant (Kappa value $=0.635$, $p$-value $<0.001$ ) .

Baschat and Weiner ${ }^{49}$ showed that a low AC percentile had the highest sensitivity (98.1\%) for diagnosing IUGR (birth weight $<10$ th percentile). The sensitivity of EFW (birth weight below the 10 th percentile) is $85.7 \%$; however, an AC below the 2.5 percentile had the lowest positive predictive value $(36.3 \%)$, while a low $\mathrm{EFW}$ had a $50 \%$ positive predictive value.

Pearce $^{7}$ showed that the sensitivity of the AC measurement (83\%) was slightly better than that of the SFH measurement (76\%) but this difference was not statistically significant. Each test had a false positive rate of about $60 \%$ which is comparable with clinical assessment.

In the present study Ultrasound machine is calibrated with Hadlock's data and the results are statistically significant and useful in detection of IUGR in the study population.

However, Mikolajczyk et al50 reported that the use of Hadlock reference ranges would lead to $60 \%$ of newborns in India being classified as small for gestational age.

Vinod K Paul et $\mathrm{al}^{51}$ in a study concluded that among the multitude of foetal growth charts available, none fulfils the requirements of an ideal foetal growth chart for our country. For a nation of our magnitude and diversity, it is desirable that we develop our own foetal growth standards based on carefully selected subjects, using robust techniques for tracking foetal biometry, and strong statistical methods.

\section{Estimated Foetal Weight \\ Mean Weight Distribution}

The mean foetal weight with Johnson's formula between was $2897.4 \mathrm{~g}$ and the mean foetal weight with USG (Hadlock's formula) is $2811.7 \mathrm{~g}$. The mean actual birth weight was 2767.4g. The mean difference in the weight is relatively lesser with narrow 95\% confidence interval by USG than Johnson's formula, USG method has relatively better method than Johnson's formula for estimation of weight. The observation is comparable with different studies 
The mean foetal weight using Hadlock's formula in present study is comparable to Alnakash et al.52 The difference with actual birth weight is comparable to Ashrafganjooei et al. ${ }^{53}$ The mean foetal weight using Johnson's formula is comparable to Parvin et al.54 The present study shows that the mean birth weight of Hadlock's formula is closest to the mean of actual birth weight, the difference being 44.3 gms whereas in Johnson's formula, difference is 130.2 gms. Thus Hadlock's formula is more accurate in predicting the actual birth weight.

Also, majority of birth weights are distributed between 2.5 to $3.5 \mathrm{~kg}$ which is comparable to Amritha et al, ${ }^{17}$ Shittu et al, 55 Watchree et al. ${ }^{14}$

\section{Standard Deviation Distribution}

The standard deviation from the mean is least with Hadlock's formula which is 488.8 gms whereas with Johnson's formula it is 501.0 gms. The results are comparable to most studies such as Amritha et al, ${ }^{17}$ Alnakash et al, Ashrafganjooei et al ${ }^{53}$ and Chauhan et al. ${ }^{56}$ Whereas Mario et al had standard deviation less with Johnson's formula than Hadlock's formula.

\section{CONCLUSIONS}

The efficacy of serial symphysio-fundal height measurement was found to be comparable with ultrasound in detection of IUGR. Hence maternal symphysis growth chart being a simple, inexpensive and sensitive screening test, its routine use should be emphasized for detection of IUGR in a developing country like India where health institutions with sophisticated technology are often inaccessible to majority of women. This method could also be taught to the paramedical personnel who can use this method to monitor foetal growth in the periphery so that cases of growth restriction can be referred early to tertiary level centers where they can benefit from more sophisticated diagnostic and therapeutic aids and good neonatal set up. It is a less cost-effective method and can be practiced more widely and does not require special training or expertise. Of the two methods studied for estimation of foetal weight, ultrasonographic method, i.e., Hadlock's formula has better predictable results in foetal weight estimation, compared to clinical method, i.e., Johnson's formula.

Recommendations-

1. Symphysio-fundal height measurements plotted on customised growth charts are recommended as an initial screening tool for intra uterine growth restriction.

2. We need to frame an ideal foetal growth chart for our country.

\section{REFERENCES}

[1] Rossavik IK, Deter RL. Mathematical modeling of foetal growth: I. Basic principles. J Clin Ultrasound 1984;12(9):529-33.

[2] Zhang J, Merialdi M, Platt LD, et al. Defining normal and abnormal foetal growth: promises and challenges. Am J Obstet Gynecol 2010;202(6):522-8.

[3] Dayanithi M. Low birth weight and premature births and their associated maternal factors. Int J Community Med Public Health 2018;5(6):2277-85.

[4] Lubchenco LO, Hansman C, Dressler M, et al. Intrauterine growth as estimated from live born birth weight data at 24-42 weeks of gestation. Pediatrics 1963;32(5):793-800.

[5] Gardosi J, Chang A, Kalyan B, et al. Customized antenatal growth charts. Lancet 1992;339(8788):2837.

[6] Westin B. Gravidogram and foetal growth. Comparison with biochemical supervision. Acta Obstet Gynaecol Scand 1977;56(4):273-82.

[7] Pearce JM, Campbell S. A comparison of symphysis fundal height and ultrasound as screening tests for light for gestational age infants. Br J Obstet Gynaecol 1987;94(2):100-4.

[8] Prechapanich J, Thitadilok W. Comparison of the accuracy of foetal weight estimation using clinical and sonographic methods. J Med Assoc Thai 2004;87(Suppl 3):S1-S7.

[9] Kumari A, Goswami S, Mukherhjee P. Comparative study of the various methods of foetal weight estimation in term pregnancy. South Asian Feder Obstet \& Gynec 2013;5(1):22-5.

[10] Sharma N, Srinivasan K, Sagayara MB, et al. Foetal weight estimation methods-clinical, sonographic and MRI imaging. Inter $\mathrm{J}$ of Scientific and Research Publications 2014;4(1):1-5.

[11] Buchmann E, Tlale K. A simple clinical formula for predicting foetal weight in labour at term--derivation and validation. S Afr Med J 2009;99(6):457-60.

[12] Johnson RW, Toshach CE. Estimation of foetal weight using longitudinal mensuration. Am J Obstet Gynecol 1954;68(3):891-6.

[13] Johnson RW. Calculations in estimating foetal weight. Am J Obstet Gynecol 1957;74(4):929.

[14] Numprasert W. A study in Johnson's Formula: fundal height measurement for estimation of birth weight. $\mathrm{AU}$ J. T. 2004;8(1):15-20.

[15] Suwannobol N, Tapin J, Narachan K. The results of the foetal weight estimation of the infants delivered in the delivery room at Dan Khunthot hospital by Johnson's Method. World Acad Sci Eng Technol 2012;6(11):5235.

[16] Torloni MR, Sass N, Sato JL, et al. Clinical formulas, mother's opinion and ultrasound in predicting birth weight. Sao Paulo Med J 2008;126(3):145-9.

[17] Amritha BA, Patrie PJ, Ashwin SP. Comparative study of various methods of foetal weight estimation at term pregnancy. J Obstet Gynecol 2004;54(4):336-9.

[18] Khan N, Jamal M. Maternal risk factors associated with low birth weight. J Coll Physicians Surg Pak 2003;13(1):25-8.

[19] Muhammad T, Khattak AA, Shafiq-Ur-Rehman, et al. Maternal factors associated with intrauterine growth restriction. J Ayub Med Coll Abbottabad 2010;22(4):64-9.

[20] Hirve SS, Ganatra BR. Determinants of low birth weight: a community based prospective cohort study. Indian Pediatrics 1994;31(10):1221-5.

[21] Ashwani N, Rekha NA, Babu MS, et al. Maternal risk factors associated with intrauterine growth restriction: hospital based study. Int J Med Res \& Rev 2016;4(12):2125-9. doi:10.17511/ijmrr.2016.i12.08. 
[22] Ferraz EM, Gray RH, Cunha TM. Determinants of preterm delivery and intrauterine growth retardation in North-East Brazil. Int J Epidemiol 1990;19(1):101-8.

[23] Odibo AO, Nelson D, Stamilio DM, et al. Advanced maternal age is an independent risk factor for intrauterine growth restriction. Am J Perinatol 2006;23(5):325-8.

[24] Mumbare SS, Maindarkar G, Darade R, et al. Maternal risk factors associated with term low birth weight neonates: a matched-pair case control study. Indian Pediatrics 2012;49(1):25-8.

[25] Acharya D, Nagraj K, Nair NS, et al. Maternal determinants of intrauterine growth retardation: a case control study in Udupi District, Karnataka. Indian Journal of Community Medicine 2004;29(4):4.

[26] De Farias AVM, Barbieri MA, Da Silva MAA, et al. Risk factors for intrauterine growth restriction: a comparison between two Brazilian cities. Pediatr Res 2005;57(5 Pt 1):674-9.

[27] Fikree FF, Berendes HW. Risk factors for term intrauterine growth retardation: community based study in Karachi. Bull WHO 1994;72(4)581-7.

[28] Shonam-Vardi I, Leiberman JR, Kopernik G. The association of primiparity with intrauterine growth retardation. Eur J Obstet \& Gynec Reprod Biol 1994;53(2):95-101.

[29] Mavalankar DV, Gray RH, Trivedi CR. Risk factors for preterm and term low birth weight in Ahmedabad, India. Int J Epidemiol 1992;21(2):263-72.

[30] Stewart CP, Katz J, Khatry SK, et al. Preterm delivery but not intrauterine growth retardation is associated with young maternal age among primiparae in rural Nepal. Maternal \& Child Nutrition 2007;3(3):174-85.

[31] Chourasia S, Agarwal J, Dudve M. Clinical assessment of intrauterine growth restriction and its correlation with foetal outcome. Journal of Evolution of Medical and Dental Sciences 2013;2(41):7944-50.

[32] Han Z, Lutsiv O, Mulla S, et al. Low gestational weight gain and the risk of preterm birth and low birthweight: a systematic review and meta-analyses. Acta Obstet \& Gynecol Scand 2011;90(9):935-54.

[33] Shapiro C, Sutija V, Bush J. Effect of maternal weight gain on infant birth weight. Journal of Perinatal Medicine 2000;28(6):428-31.

[34] Omani-Samani R, Sepidarkish M, Safiri S, et al. Impact of gestational weight gain on cesarean delivery risk, perinatal birth weight and gestational age in women with normal pre-pregnancy BMI. The Journal of Obstetrics and Gynecology of India 2018;68(4):25863.

[35] Goqiia TE, Kintraia NP. Intrauterine growth retardation in preterm labor and delivery. Georgian Med News 2005;(129):30-3.

[36] Meyberg R, Boos R, Babajan A, et al. Intrauterine growth retardation-perinatal mortality and postnatal morbidity in a perinatal center. Z Geburtshilfe Neonatol 2000;204(6):218-23.

[37] Zeitlin J, Ancel PY, Saurel-Cubizolles MJ, et al. The relationship between intrauterine growth restriction and preterm delivery: an empirical approach using data from a European case-control study. BCOG 2000;107(6):750-8.
[38] Driul L, Londero AP, Martina DM, et al. Intrauterine growth restriction and pregnancy outcome. Minerva Ginecol 2008;60(3):231-8.

[39] Morse K, Williams A, Gardosi J. Foetal growth screening by fundal height measurement. Best Pract Res Clin Obstet Gynaecol 2009;23(6):809-18.

[40] Rosenberg K, Grant JM, Hepburn M. Antenatal detection of growth retardation: actual practice in a large maternity hospital. $\mathrm{Br} \mathrm{J}$ Obstet Gynaecol 1982;89(1):12-5.

[41] Hall MH, Chng PK, MacGillivray I. Is routine antenatal care worthwhile? Lancet 1980;2(8185):78-80.

[42] Rondó PH, Filho MNL, Valverde KK. Symphysis-fundal height and size at birth. Int J Gynaecol Obstet 2003;81(1):53-4.

[43] McDermott JC. Fundal height measurement. In: Wildschut HIJ, Weiner CP, Peters TJ, eds. When to screen in obstetrics and gynecology. Philadelphia: Elsevier 2006: p. 326-43.

[44] The Royal College of Obstetricians and Gynaecologists. Small-for-gestational-age fetus, investigation and management (Green Top Guidline, No. 31). 2nd edn. www.rcog.org.uk. 2013.

[45] Robert PJ, Ho JJ, Valliapan J, et al. Symphysial fundal height (SFH) measurement in pregnancy for detecting abnormal foetal growth. Cochrane Database Syst Rev 2012;(7):CD008136.

[46] Quaranta P. Symphysiofundal height measurement in monitoring intrauterine foetal growth. Am J Obstet Gynaecol 1978;131:643.

[47] Challis K, Osman NB, Nordahl G, et al. The impact of adjustment for parity and mid-upper-arm circumference on sensitivity of symphysis-fundus height measurements to predict SGA foetuses in Mozambique. Tropical Medicine \& International Health 2003;8(2):168-73.

[48] Walraven G, Mkanje RJ, Van Roostmalen J, et al. Single pre-delivery symphysis-fundal height measurement a single predictor of birthweight and multiple pregnancy. Br J Obstet Gynaecol 1995;102(7):525-9.

[49] Baschat AA, Weiner CP. Umbilical artery Doppler screening for detection of the small fetus in need of antepartum surveillance. Am J Obstet Gynecol 2000;182(1 Pt 1):154-8.

[50] Mikolajczyk RT, Zhang J, Betran AP, et al. A global reference for foetal-weight and birthweight percentiles. Lancet 2011;377(9780):1855-61.

[51] Jain V, Paul VK. Foetal growth standards: does one size fit all? Proceedings of the Indian National Science Academy 2016;82(5):1449-63.

[52] Alnakash AH, Mandan DR. Foetal body weight: how far the clinical and sonographic estimations can coincide and their correlation with the actual birth weight. Iraqi J Comm Med 2013;(2):180-3.

[53] Ashrafganjooei T, Naderi T, Eshrati B, et al. Accuracy of ultrasound, clinical and maternal estimates of birth weight in term women. Eastern Med Health J 2010;16(3):313-7.

[54] Parvin Z, Shafiuddin S, Uddin MA, et al. Symphysio Fundal Heifht $(\mathrm{SFH})$ measurement as a predictor of birth weight. Faridpur Med Coll J 2012;7(2):54-8. 


\section{Jemds.com}

[55] Shittu AS, Kuti O, Orji EO, et al. Clinical versus sonographic estimation of foetal weight in southwest Nigeria. J Health Popul Nutr 2007;25(1):14-23.
Original Research Article

[56] Chauhan KP, Patel UJ, Leuva BR. Comparative study of various methods of foetal weight estimation at term pregnancy. J Integrated Health Sciences 2013;1(1):3-6. 